\title{
Threat perception of the rural-urban migration as a linkage to the rise of crime: Bangladesh perspective
}

\author{
Taslima Khanam \\ Department of Law \\ International Islamic University Chittagong, Bangladesh
}

\begin{abstract}
At present the rise of urban crime falls within the gripping focus of criminal justice and criminology. Researchers endeavor to figure out urban schemes of crime which linked with rural-urban migration. Although, rural-urban migration mostly concerns the subject of sociology, this article viewed from jurisprudential perspectives under the sociological school to study social doctrines in relation with the migration as social phenomena and to criticize as to their relation to social condition and social progress. This observable fact of rural-urban migration could also be apprehended as a supply of the intensifying and distressing crisis in urban areas which is rising violent behavior and criminal activities. This article uncovers the cause and effect of increasing crime under interrelation between migration and the security précised by the law and order environment. The author finds the needs and changes of the society due to the migration of a huge mass of people from rural to urban areas in Bangladesh. Finally, the paper recommends the balance of conflicting interests from social, political and ethical stance to facilitating the policies and laws concerned.
\end{abstract}

Keywords Urban migration, Social disorganization, Crime and threats, Social and moral urge

Paper type Review paper

\section{Introduction}

In the development of trade and industry, rural-urban migration is deemed reasonably advantageous in a social context, as the migration would allow individuals to move from localities of very low collective marginal objects, to places where their margin al substances are far above the ground and also increasing summarily. Domestic migration is in reality a usual course where the residual labour is fled from the countryside region to provide manpower required for urban industrialized enlargement. However, latest practice in least developed countries like Bangladesh reflects it obvious that rates of this migration have a tendency to go beyond rates of urban job establishment and to go over significantly the

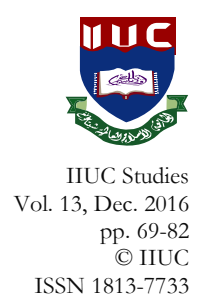


inclusion aptitude of production and urban community arrangement. While the massive invasion of rural inhabitants meets up the labour demand of urban economic development, the migrant population also causes a variety of social and economic crisis such as crime in urban areas. This linkage can be explained through the emergent internal migration in the country, exceeding the power of the private and public segments of urban areas to absorb added man power. Sequentially, the anticipations of the migrants of having a better standard of living are not being achieved, instead of this a sense of relative deprivation and disappointment is spread out, and thus pushing rise to violent and hostile activities. Moreover, as migrants must be habituated to the new-fangled urban life, in a wide social context expressively by leaving behind their previous lifestyle, they are always stained in identity crisis. This swells their exposure of involving political or religious extremist groups based on misconceptions of politics and religion. Rural-urban migration cannot be measured as the only basis for rising crime but could undoubtedly be ascribed as a factor of increasing crime.

\section{Theoretical approaches to the link of Rural-Urban Migration \& Crime}

Theoretical framework for the article has been formed taking inferences from three basic theories that exist in sociology and anthropology. These are social disorganization theory, culture of poverty theory and human capital theory.

\subsection{Social Disorganization Theory}

Chicago School developed the social disorganization theory as the most imperative one. There are many famous social scientists who have contributed the theory and thus, a number of complementary theories exist on this subject. However, the explanations by Shaw \& McKay, Faris and Sampson have been more relevant in this regard. Their research was based on dependent variables in crime and delinquency rates and host of free variables like economic conditions with square-mile areas, population defer, and ethnic heterogeneity. From the available literatures, it is difficult to define the social disorganization. But it passes on to the malfunction of social organization and institutions in the city or specific group of people (e.g., school, company, policing, real estate, cluster networking). It is relevant to highlight three important postulates of this theory:

a. Shaw and McKay defined social disorganization as "the inability of local communities to realize the common values of their residents or solve 
commonly experienced problems." Three long-established sources of social disorganization are: residential instability, racial/ethnic heterogeneity and poverty. These were also the three conducts in which criminal way of life took entrenched into communities. The literature also explained three sources:

i. Residential Instability/Mobility: It denotes populace yield of shifting residents or looking to shift frequently.

ii. Racial/cultural Heterogeneity: Diverse races, cultures, and language form the sensitivity of overwhelming hurdles (variety not occurring as a first-rate mania) with people dividing themselves and keeping away from evocative relations or general view to share.

iii. Poverty: Substantial segment of the residents are paying attention on survival in a region they would much like better to depart as soon as probable due to poverty.

b. Shaw and McKay gave interesting idea about poverty. They said," Poverty, by itself, is never a root of crime; it just facilitates crime by denial of adequate resources to deal with crime." Shaw and McKay emphasized that poverty areas have a tendency to have high rates of residential mobility and ethnic heterogeneity, risky for communities in those areas to stay away from fetching socially disorganized. The two population variables: mobility or turnover which hinders familiar structures of societal command, and heterogeneity that hampers pursuit to work together on general crisis; turn into the crucial underlying variables for social disorganization theories.

c. Concept of social disorganization extended by Faris (1955), clarifies community pathways and communal crisis in wide-ranging, involving offense, psychological infirmity, and mass aggression. He defined organization as explicit and continuing samples of corresponding relationships, and explained collective disorganization as the declining or devastative relations that grip in combining a social organization. Faris central proposition about crime is indeed significant as he said that a crime pace is a mirror image of the level of disorganization and controlling methods of the general public. Crime in its spin too adds to disorganization, and ineptitude of these conformist systems is in particular to be expected in large, fast rising industrialized areas where this disorganization allows extremely structured crime as at the same time as less organized sets of combined and individual offense or felony. 


\section{IIUC STUDIES, 13}

d. Sampson (1993) asserts that most violent crimes are committed by the teenaged groups, predominantly street gangs, and later, a gang associate will turn out to be a full-time offender if community controls are inadequate to deal with antisocial activities at an early age. He supports Shaw and McKay in assertion of that if the ancestors and relatives fail to provide an adequate supervision or relatively good socialization; offspring from wrecked families are more apt to connect aggressive gangs unless some others take the parents' position. However, kids from yet unsound relations are not as much of possibly to be inclined by stare groups in a society where the majority family are integral. United communities are more probable to mark gangs and outsider, inform any unusual to their parents, and get ahead of caution along. Elevated rates of suburban mobility and public housing disorder the aptitude to ascertain and preserve social bonds. In many communities, religious institutions, charities, schools, and the community police act as substitutes for family unit. However, underprivileged and unsound communities frequently lack the organization and political links to get funds for combating crime and offering young people an alternative to deviant activities. Sampson ends with the assertion that the structural aspects of social disorganization have consequence in violence to elucidate macro level variations. Thus, social disorganization perhaps generates crime by dividing communities from the mainstream way of life.

\subsection{Culture of Poverty Theory}

'Culture of Poverty' concept introduced by Anthropologist Oscar Lewis in 1959 explains the cycle of poverty. This social theory stands on the notion of the poor's distinctive value system. The supposition implies, the poor stay in poverty for the reason of their adjustments to the impediment of poverty. Lewis gave some seventy attributes that signify the subsistence of the culture of poverty. Some of the points Lewis mentioned are:

a. The poor do not have effectual partaking and assimilation in key institutions of society in large. They allege to go with quite a few basic ideals; however for the most part, are not in fact observed at all.

b. Inadequate housing situation, crowding, extroversion, and a least amount of association characterize the life of the poor in the culture of poverty. Hardly ever comfortable momentary groupings or voluntary alliances within slums are available here. 
c. The dearth of youth, as a distinctively prolonged and secluded stage in the lifecycle, is a trait among some of the poor; as the same as early instigation into sex, open unions or consensual marriages. There is also a drift to female-centered family.

d. A strong sense of marginality, feeling of not belonging, helplessness and dependency is the ultimate reality of people in the culture of poverty. They are similar to aliens in their own realm, convinced that the existing institutions might not serve their interests and wants. This sense of powerlessness is a persistent sentiment of inferiority and individual disgrace. This is the true reality of the slum dwellers.

In brief, the culture of poverty is both an adjustment and a response of the poor to their trifling situation in a class-stratified and exceedingly isolated society. However, it is not merely an adaptation. Once it comes into reality, it effects on children and also has a tendency to go on with generation to generation. By the moment in time, children in slum are seven or eight years old, they habitually have engrossed the critical values and manners of their sub-culture and are not sensitively able to take inclusive lead of changed stipulations or enhanced opportunities which might happen in their life span.

\subsection{The Human Capital Theory}

To turn out economic value, human capital refers to the preservation of competences, knowledge and personality traits embodied in the capacity to do manual labour. It is the power gained by a worker through appropriate learning and practice. Human Capital Theory presumes, people have access on the way to more or less equal information. But once we apply this in the context of our migrants who are forced, we cannot find the same is prevalent. Our poor migrants do not reflect the image of human capital theory. They do not judge their capability and asses how much benefit they will get in the place of destination.

\subsection{Interrelationship of the Theories}

The rural-urban migration, practically is taking place due to the natural reasons. The graph of migration towards the urban areas is increasing. One of the important economic reasons for this internal migration is the unemployment. Environmentalists define the causes as, rural circumstances and attraction by the urban areas - push and pull factor. In all cases the large numbers of migrants find their destiny in the slums or squatters of the urban areas. Most of the slums match the context of the 


\section{IIUC STUDIES, 13}

social disorganization theory where formal social control mechanism does not function. If so then, it is assumed that crime is a natural phenomenon in those slums or squatters. The poor migrants, who are forced to migrate to urban area, usually operate with low human capital. They survive by the character of the culture of poverty. And as a natural phenomenon these people become influenced by the elements of social disorganization. So, there are interrelations of the circumstances that can be found existing in the theories mentioned above.

\section{Rural-Urban Migration: The Cause \& Effect}

It is important to firstly realize that why people do migrate and what its impact is. This can be clarified under the following heads:

\subsection{Push and pull factor:}

Migration is the mutual upshot of both push and pulls factors where both these factors are functioning concurrently. Migrants, in response to the optimistic factors at destination are all the time positively preferred from the origin, whereas migrants responding to the negative factors at derivation are always pessimistically selected from there.

At this point, we find two factors: rural circumstances and attraction created by the city. Rural circumstances are disaster, poverty, landlessness and different social problems. Due to this reasons people migrates from rural area. Basing on the several studies refer to the push-pull or drivedrag factors, at rural end push factors may possibly be identified as:

a. Population strain, adverse man-land fraction, landlessness and poverty.

b. repeated and relentless natural catastrophe like hill slide, riverbank erosion, floods, and cyclones.

c. Unstable law and order situation.

d. Lack of economic, social and cultural opportunities.

e. Inadequate edification and health facilities, etc.

Pull/ drag factors are:

a. Potential for employment.

b. A safer atmosphere. 
c. Better service provision.

d. Greater wealth.

e. Political security.

f. Less risk of natural hazard.

g. Adequate social, cultural, educational and health facilities, etc.

\subsection{Greater inequality in urban populace linked with higher levels of urban crime.}

Rural-Urban migration is a dominant sign of local inequality, whether in requisites of opportunities or lifestyles. In the process of urbanization, which is the consequence of the migration, urban areas have increased in dimensions. However, rapid growth rate of this urbanization have created a pressure on the livable place due the limitation of physical barrier of the township. It has increased the quantity of slum areas in the city. These areas are unplanned, and there exists social disorganization. As migrants bring away their required consumption into the new settlement, the movement from rural to urban areas creates a downbeat impact on the value of rural life. This is a major concern for social scientist and environmentalists. But, this aspect of social phenomenon has a link with social crime, and it makes spillover effect in the national security. There is no much research works in this perspective of security domain. But, theoretical references reveal that such migration will cause a social disorganization, and will cause crime and violence in the area where the migration takes place. The rationale behind the rural-urban migration to cause an increase in crime is perceived from very simplistic argument. In a society where certain control mechanism exists, people are always bestowed with positive control. An organized social behavior and culture make certain bindings in the conduct of the people belong to that society. In contrast, when large number of people lives at a place where no one cares for anyone they are not directed by any community values. In other word there people will be displaying negative trends of behavior. The result is due to the social disorganization. This circumstance of the social environment assists the people to do crime and violence. Migration creates a similar scenario in the slums and squatters where uneducated, unaware and ill treated migrants may easily be vulnerable to the opportunities in the criminal racket. Urban migrants survive in casual settlements beneath a pitiable environmental and economic conditions could cause social segmentation as subgroups inside the society pull out themselves to keep their individual interests. Moreover, it is evident by the 


\section{IIUC STUDIES, 13}

all-inclusive report of UNDP 2002 on human security that lots of bylaws and regulations in Bangladesh are unfriendly to the poor and put an outlying detrimental impact on them, regardless of legality. Therefore, general public, particularly the poor, do not undergo satisfactory security. These social molds of disparity escort to social segregation and biological absorption of the destitute, which in turn gives rise to structural hurdles and cultural variations that, demoralize social organization and undermine the control of crime.

\subsection{Crime scenario as an outcome of Rural-urban migration}

Overall crime, how far aggressive or less, is conceded by a variety of unusual individuals and groups who work for ulterior objects that go from hunger to self-indulgence, and to political affairs. The security of urban area becomes threatened by many internal and external crime and violent actions. Among them: mastaani or induced violence, toll assortment, arson in slum, land grabbing, drug and arms dealings, slaughter, abduction, material, psychological and sexual harassment and exploitation of spouse/ kids, etc are most commonly reported crime. In the taxonomy of crime, the actions by the slum dwellers are treated in the low category. A person involved in the petty crime may become famous by a single incident. This finding justifies that we have to remove our fallacy regarding the effect of crime by the people who subsist in slums and squatters in the city area. The prevailing sense of deprivation among the slum dwellers may trigger the significant incident which would pose threat to national concern. The principal cause identified, for which unemployed/underemployed migrants get into the crime, is getting trapped by the gang. The case study and the empirical findings suggest that crime is not mostly a survival option in the slums, which many of us hold as perceived idea. It is important to learn through interview that slums are the exits for the drugs to the dealer. As a result the availability of drugs in the slums and squatters is a common phenomenon. Some of the poor migrants who live in slums, are not employed or under employed consider a casual assistance to the drug dealer is way of little earnings. Thereby, they expose vulnerability to the crime gang. The situation unawareness leads them to the uncertain consequences. In addition arms and narcotics trafficking add to the severity of the crime. Since there is no informal control mechanism exists in that area, absence of internal monitoring coexists. This invites frequent intrusion by the criminal racket. But, Proper management of the slums and squatters and careful intervention by the law enforcing / security agencies can hold down this crime. 
The reason for the migration of poor people who stays in the slums and squatters are mostly attributable to the push factor. They live in marginality and helplessness. Thereby, the sense of deprivation prevails among these poor migrants. Social negligence and some time disrespect by law enforcing agencies add fuel to their burning. This factor increases the vulnerabilities of the migrants who live in the slums and squatters to the opportunities of getting into the criminal racket. These transgression and sadism are neither précised simply a societal peace hinder, but besides act like a barrier to improvement that grind down the poor's soul, substantial and social speculation, and with high linked economic costs. Offense and violent behavior distress all segments of society: the women and men, young and old and rich and even more - the poor. It is therefore important to first realize the future implication of such crime actions that are common to the slums. This apt realization will unfold the scope to think why this poor people who are mostly migrants get involved in different crimes. So, addressing crime and adopting policy to deal with this civic spate is a concern that is ever more fetching precedenceglobally as well as in our state.

\section{Rural-urban Migration as a contributor to the rise of Crime: Bangladesh perspective}

At the present, Bangladesh is $9^{\text {th }}$ most densely inhabited realm in the earth and her population is estimated to reach 190 million in 2025. United Nations study (UN 1991) also evidenced of contrasted increasing percentages of rural and urban inhabitants.

Annual growth rate Urban-rural population in Bangladesh (1941-2001)

\begin{tabular}{ccccc}
\hline \multirow{2}{*}{ Year } & \multicolumn{2}{c}{ Rural } & \multicolumn{3}{c}{ Urban } \\
\cline { 2 - 5 } & $\begin{array}{c}\text { Population } \\
\text { (Million) }\end{array}$ & $\begin{array}{c}\text { Annual growth } \\
\%\end{array}$ & $\begin{array}{c}\text { Population } \\
\text { (Million) }\end{array}$ & $\begin{array}{c}\text { Annual growth } \\
\%\end{array}$ \\
\hline 1941 & 40.45 & 1.6 & 1.54 & 3.6 \\
1951 & 42.34 & 0.5 & 1.83 & 1.7 \\
1961 & 52.58 & 2.2 & 2.64 & 3.7 \\
1974 & 70.39 & 2.3 & 6.00 & 6.3 \\
1981 & 76.35 & 1.2 & 13.56 & 11.6 \\
1991 & 89.80 & 1.5 & 22.5 & 4.7 \\
2001 & 75.32 & 1.3 & 15.64 & 5.8 \\
\hline
\end{tabular}

With distinct large and small urban areas, six major cities of Bangladesh have been denominated with the position of city corporations, administered by metropolitan establishments. Further, as urban areas, 271 municipal establishments, or pourashavas, are found most of those are not more than rural towns for want of the condition required for being 


\section{IIUC STUDIES, 13}

recognized a municipality. The six biggest cities of Bangladesh consist of more than half of the national urban population, and Dhaka alone includes almost one-third of the national urban population.

Migration becomes the most overriding factor of population intensification, particularly in large urban areas. Dhaka, the capital, creates a center of attention between 300,000 and 400,000 fresh migrants each year. Bangladesh, similar to other least developed countries (LDC), has a huge rural population and agricultural labour force. The large rural-urban migration in Bangladesh, in contrast with other least developed countries, is characterized to have comparatively strong drive factors on the one hand, and strapping drag factors also. Both drive and drag factors have contributed to migration in Bangladesh. The major feature that pushes people to go away from their dwellings of country side is the regular reappearance of natural calamities, which destabilize agricultural growth and cause food crisis. In disparity, the principal issue that draws people to urban insides is the existence of a large informal sector like rickshaw pulling, shops in the roadway and hawking which offers quick employment opportunities or even higher income. The expansion of some sub-sectors of industry like garments also exerts a strong pulling force for migration. We are creating lot of opportunities in the mega cities, like, Dhaka city: over $60 \%$ of industries located in Dhaka; about 3 million people work in garments; huge construction sector engages large population; about 8 lakh rikshaw pullers and large number of housemaids. These sectors are huge consumer of migrants.

Now what about the relation of crime with these migrants is? Rural to urban migration which results urbanization has the link with crime and criminal activities. The urban facilities as meager to the rate of urban growth cause a competitive race of consumption among the city dwellers. This can cause a sense of deprivation to the poor migrants and make them vulnerable to the opportunities in the criminal. In 2005, statistics around 35 percent of urban people of Bangladesh survived in slums, transversely its six city corporations. The mainstream of those shifted migrants are the rural poor bearing for slums in towns and municipalities. The over-crowded life in this slums, squatters or pavements may lead to social disorganization and even a sub-culture of violence. A large mega city like Dhaka offers many opportunities for criminal activities. Some of these crimes may include international drug traffic, international smuggling and terrorism which may pose a serious threat to national security. Various criminal activities are carried by these poor slum dwellers as a means to sustain their livelihoods. People, who used to live in the rural area, had maintained a kind of rural social organization. There is an informal control mechanism effective in the rural social sector. But the people coming to the urban area for employment immediately get exposed to the loneliness of the city. It creates an organizational 


\section{Threat perception to the rise of crime 79}

breakdown. In that situation anyone can be involved in the crime or criminal activities. Most of these people come to Dhaka/Chittagong for job opportunities. These people living in the slums are needy; they can be easily purchased. This is why they get involved in crimes. In most cases the crimes that are seen are drug dealing, sex abusing etc. And it is very rightly pointed out that they are used by the politically influential person and Godfathers. They give incentive to these people to stay there and they used them for their political ambition. For the above situation the poor migrants should not be blamed. A child who should be socialized in proper way does not get this scope in the slum. Instead, they find a bad environment and do not get security of life. In such context when an unsecured child in raised in the slum they pick up the bad elements of the surroundings. They easily get involved in drugs dealing. They are used as carrier of drugs and in some occasions of arms. These people develop the criminal mentality; get involved in crime many of them start snatching get into the chain of criminal racket. During the political unrest or public order management the slum dwellers as a whole get involved. There are off the recorded local leaders in each slum known as mastaans who represent ahead their political link to justify their control and power. The unembellished paraphrase of mastaan is muscleman, and these peoples take part in a character of a middleman holding political privileges especially in election period. Besides they are used by the elites as admittance to land and control of property issues, including the intimidation of eviction to others heinous crime related to the land matters. The intricate network that consisting of muscleman or mastans/ shontrashis, political touts, local government and police, has a booming dealing in the slums. These earnings get shared amongst the persons building up the network.

Thus these sections of migrants exacerbate the security situation. In the language of criminology they are prospective criminal. The case study of Picchi Hannan bears the testimony.

Md. Picchi Hannan alias Picchi Hannan was born at Shantoshpur village in Faridganj Thana in greater Chandpur District. His father's name was Waziullah. Hannan migrated to Dhaka in his very early life. Coming to the city he started working as task boy (Tokai) in the general marketplace of Karwan Bazar who was directed to collect the money from the vendors who used to make queue in the Bazar. Shahadat who was a lineman used to grab share out of this collected money. An errand boy - Picchi Hannan, was first picked up and sheltered by Shahadat for exortion of money from the Bazar. Thus, Picchi Hannan was allured to the wrong doing. He used to do petty crime under the shelter of criminal leader in and around the marketplace.

Hannan, known as Picchi Hannan, as a thief and a growing terrorist, was first arrested in 1995. In jail he became intimated with a distinguished 


\section{IIUC STUDIES, 13}

terrorist, named Sweden Aslam. Many state that later than this stumble upon and his free from jail, Hannan turned a giant terrorist and in 1997, he factually took over the criminal world actions of Aslam. In 2004, Rapid Action Battalion (RAB) members on the night of June 24 raided a house in Sector 11 in Uttara of the city to nab Hannan, but later on, he along with his associates escaped from the custody with injuries following a gun fight. Finally 26 June, 2004, Picchi Hannan was killed in an encounter with RAB near Ashulia in Savar.

\section{Concluding observation}

On the basis of theoretical framework and pragmatic evidence it is revealed that rural-urban migration cause threat to the urban security. Not only that, urban transgression and aggression also engender a climate of fear that are severe stress and threats to the solidity and socioenvironment of city areas, to sustainable economic growth, and also a peril to the value of life and human rights. Now it becomes a vital issue of increasing the crime in cities. But these poor migrants who perform with low human capital cannot be blamed on the whole. It is quite clear that in most occasions they are victimized by external influence, and there are different dimensions. However, in order to take correct policy option the responsibilities should share by all.

The customary retort to growing intensity of crime and violent behavior has been one of control or repression. This traditional way of dealings with this problem highlights on mitigating the crisis subsequent to committing the crime. It is generally correlated to reinforcing the law and establishment of justice, escalating law enforcement aptitude, and initiating harsh punishments for prevention and suppression of aggression. Secondly and correspondingly, effective policy response is one of the prolong prevention of crime. The vital point is to prevent the criminal activities from taking place in the first set by a systematic evaluation to date and thoughtful addressing the causes of crime and violence. Thus, international practices with different strategy approaches recommend to the problem of urban crime and hostility that an incorporated agenda including a variety of potency can show the way to an effective reduction strategy of preventing urban crime and violence. This agenda for local action is supposed to base on a comprehensive problem-solving and participatory method, and consist of several rudiments of:

a) Judicial/policing reform - undertaking that justice, equality, and access to due process is ensured in the everyday actions and dealings of general public and reducing the communal dread of crime; 
b) Social prevention - aimed at versatile community motivated agenda that deal with the grounds and threat factors of inner-city felony and violent behavior;

c) Situational preclusion - actions that diminish opportunities for particular crime and hostility dilemma in the course of urban spatial involvements and slum upgrading; and

d) Moral measures - dealings that enrich moral values based on religious aspects as to humanity.

Mostly, it involves a mutual local exposure, political commitment, strong leadership, and immediate and gradual strategy. A sound coordinated effort is required to bring an optimistic result to the consequences of rural-urban migration in the perspective of security threat. Centre for Urban Studies (CUS) along with Local Government Authority and Local Administration may be utilized to prepare ruralurban migration statistics to formulate an official data source. A one year plan may possibly be under taken to record relevant information of all the slums in the Dhaka City. Progressively it ought to be executed in other urban areas. Local Government may make sure basic education with moral values for the children and family living in the slums at priority, with in structure of national education policy.

In the final analysis problems are aggravated by the lack of an allinclusive strategy and the absence of an organized course of action. Hence, future security threat from rural-urban migration can be solved only through substantial reduction of urban poverty. The other effective step that government should take is the decentralization. This will give the solution along with remedies of many other issues. Relocation of garments to the remote places will reduce the good numbers of inhabitants from the slums. This will cut down the figure of crime in the Cities. Government security agencies need to develop the futuristic scenario of the security threat that can be caused by rural-urban migration. This again requires a more focused pro-poor development policy and greater integration of Government Organization and Non Government Organization interventions. Moreover, a social and moral awareness has to be created in the society to build up the religious urge towards humanity and social welfare.

\section{Notes}

1. Shaw and McKay, researchers at the Chicago School studied and noticed that the same neighborhoods in Chicago seemed to have about the similar delinquency rates in spite of which ethnic group moved in. They asserted that delinquency was not caused at the individual level, but is a usual response by normal individuals to abnormal situations. Thus, if a community is not self-policing and ineffectively policed by outside agencies, 


\section{IIUC STUDIES, 13}

some individuals will exercise unrestricted freedom to express their dispositions and desires, often resulting in criminal activities.

2. Centre for Urban Studies (CUS), NIPORT, and Measure Evaluation, Slums in Urban Bangladesh: Mapping and Census 2005, Dhaka and Chapell Hill 2006. Municipalities must have a total population over 15,000 inhabitants, a population density over 2,000 per square mile, and have over three-quarters of the population engaged in industry other than agriculture.

\section{References}

Ullah, A. K. M. A. (2004). Bright City Lights and Slums of Dhaka city: Determinants of rural-urban migration in Bangladesh. Migration Letters, 1(1), 26-41.

Siddiqui, T. (2008). Migration and development-pro-poor policy choices. The University Press Limited.

Sampson, R. J., \& Grove, W. B. (1989). Community structure and crime: testing social-disorganization theory. American Journal of Sociology, 94(4), 777-802.

Parker, S., \& Kleiner, R. J. (1970). The culture poverty: an adjustive dimension. American Antbropologist, 72, 516-527.

Begum, A. (2007). Urban Housing as an Issue of Redistribution through Planning? The Case of Dhaka City. Social Policy \& Administration, 41(4), 410-418.

Islam, N., Shaf, S. A., \& Nazem, N. I. (2007). Urban poverty alleviation through access to land and housing. Paper presented at the alleviation of urban poverty through good governance conference, Bangladesh University of Engineering and Technology and UNDP, Dhaka.

Sen, B., \& Hulme, D. (2006). The state of the poorest 2005/2006: chronic poverty in Bangladesh, tales of ascent, descent, marginality and persistence. Dhaka and Manchester: Bangladesh Institute of Development Studies and Chronic Poverty Research Centre.

BIDS. (2002). On urbanization and the urban poor in Bangladesh.

World Bank. (2009). Dhaka: Improving Living Conditions for the Urban Poor. Bangladesh Development Series, Paper 17, Dhaka: World Bank Office, Retrieved November 10, 2016, from. www.worldbank.org.bd/bds

Centre for Urban Studies (CUS), NIPORT, \& Measure Evaluation, (2006). Slums in Urban Bangladesh: Mapping and Census 2005, Dhaka and Chapell Hill.

GOB. (2009). Bangladesh climate change strategy and action plan. Dhaka: Ministry of Environment and Forests.

\section{Corresponding author}

Taslima Khanam can be contacted at: law4humanity@gmail.com 